\title{
Prospecting the Effects on Abalone (H. discus) Growth under Low-Salinity Stress after Feeding Citrus Peel (CP) and Ecklonia cava disuse (ECD) as Feed Additives
}

\author{
Min-Seok Jwa ${ }^{1}$ and Chang-Yu Hong ${ }^{2, *(\mathbb{D})}$ \\ 1 Department of Future Strategy Research, Jeju Research Institute, Busan 63147, Korea; jms69@jri.re.kr \\ 2 Division of Global \& Interdisciplinary Studies, Pukyong National University, Busan 48513, Korea \\ * Correspondence: hcy@pknu.ac.kr; Tel.: +82-51-629-5623
}

Citation: Jwa, M.-S.; Hong, C.-Y. Prospecting the Effects on Abalone $(H$. discus) Growth under Low-Salinity Stress after Feeding Citrus Peel (CP) and Ecklonia cava disuse (ECD) as Feed Additives. J. Mar. Sci. Eng. 2021, 9, 707. https://doi.org/10.3390/jmse 9070707

Academic Editor: Gualtiero Basilone

Received: 8 May 2021

Accepted: 24 June 2021

Published: 26 June 2021

Publisher's Note: MDPI stays neutral with regard to jurisdictional claims in published maps and institutional affiliations.

Copyright: (c) 2021 by the authors. Licensee MDPI, Basel, Switzerland. This article is an open access article distributed under the terms and conditions of the Creative Commons Attribution (CC BY) license (https:// creativecommons.org/licenses/by/ $4.0 /)$.

\begin{abstract}
This study addressed the effects of adding citrus peel (CP) and Ecklonia cava disuse extract (ECD) in the diet of abalones, which are a highly utilized marine species in Korea. As interest in abalone farming is increasing around the fishing community, the installation of land tanks and fish farms on the southern coast and Jeju Island in South Korea is spreading remarkably. In order to create the best opportunities for survival and reproduction, immunity to disease, and growth potential of abalones, we must consider the diet implemented in abalone farming. The survival rate of abalone has shown positive results when their diet is supplemented with CP and ECD. Our research also concluded that the addition of ECD may have a significant effect on the abalone growth and physiology.
\end{abstract}

Keywords: Abalone (H. discus); Ecklonia cava; citrus peel; low salinity; survival rate; diets

\section{Introduction}

As interest in abalone marine life has increased, means of catching and storing them have also become significantly more common along the southern coast of South Korea [1]. Abalone (H. discus) is rich in protein and taurine, so it has benefits when used in skin care, postpartum cooking, fatigue recovery, and in the prevention of myocardial infarction.

Making a suitable environment for abalone is the most important consideration. An ideal environment can potentially aid in growth and their ability to fight off disease. For these benefits, the feeding supply should also be considered. Unlike the environment and the sources of diseases, which cannot be controlled totally at the farm, diets are under full control.

In particular, diet is an important factor that accounts for more than half of the operating costs of aquaculture [2]. It is one of the more important factors that can be modified artificially.

Raw seaweed and raw kelp are supplied as food in abalone aquaculture. The supply of these natural foods is not only unstable, depending on the crop conditions, but the price fluctuations are also severe and the effect on growth is reported to be lower than that of nurtured feeds [3-6]. Accordingly, some studies on the development of abalone feed have already been carried out in some countries such as Australia, China, Japan, Chile [7-11]. These researchers aim to develop economically blended feeds suitable for the domestic aquacultural situation. Citrus peel, which is produced in the citrus agriculture industry-a major primary industry in Jeju Island, is a byproduct generated after processing citrus fruits. It is a great financial burden for the agricultural households of Jeju because it costs a lot to dispose of citrus peel.

Citrus fruits are known to contain various flavonoid compounds, which are polyphenols, such as naringin, hesperidin, naringenin, hesperetin, nobiletin, and tangeretin; thus, they have good physiological activity $[12,13]$. It has also been reported that citrus peel, a 
byproduct of citrus fruits, contain a large amount of flavonoids and thus have antioxidant activity. Research to extract these functional substances is being actively conducted [14].

In addition, Ecklonia cava is a perennial brown algae belonging to the taxonomic rank Phaeophyta, Phaeophyceae, Laminariales, Laminariaceae. It is one of the largest seaweed species in Korea, along with other members of the genus Ecklonia. As phlorotannin is known to have excellent antioxidant, antihypertensive, antithrombotic, and anticancer properties, it is emerging as an important ingredient in the "health food" and pharmaceutical industries $[15,16]$.

However, because the Ecklonia stalk, which accounts for approximately 25\% of Ecklonia cava weight, is discarded without being used as a processing byproduct, a method of utilization is required. Because polyphenolic substances have been reported to impart high antioxidant activity in the stems of Ecklonia cava [17], we expect the use of Ecklonia byproducts in the feed of abalones, which contain seaweed, to create new added value as well as aid environmental preservation.

Therefore, this study was conducted to evaluate the effects of citrus fruit and Ecklonia byproducts, on growth and salinity stress, as additives for abalone blended feed, which is a major aquaculture target species in Korea.

\section{Materials and Methods}

\subsection{Experimental Materials and Breeding Management}

The abalone ( $H$. discus) used in the experiment was purchased and used at a private marine life farm near Jeju City, Jeju Province. Individual abalones with an average length of $3.8 \pm 0.2 \mathrm{~cm}$, a width of $2.5 \pm 0.2 \mathrm{~cm}$, and a weight of $6.4 \pm 0.1 \mathrm{~g}$ were used. The experimental abalones were bred at $18 \pm 0.3^{\circ} \mathrm{C}$ for one week beforehand, and after they were acclimatized, bred in a tank with a circulatory filtration system. At this time, the salinity was maintained at approximately $33.5 \mathrm{psu}$ and air was supplied by putting a shelter through a PVC pipe that was cut vertically $(\varnothing 20 \mathrm{~cm}, \mathrm{~L} 20 \mathrm{~cm})$. During the preliminary breeding period, raw seaweed, weighing $2 \%$ of the abalone weight, was put in the tank as a food source and 80 abalones were placed in each tank.

\subsection{Production of Feed for Abalones}

In this breeding experiment, a total of four types of feed were prepared and each experimental group had three replicates. Casein was used as the main protein source, and fish oil and soybean were used as the dextrin lipid sources. The amount of carbohydrate sources was controlled using oil, and wheat flour was added to control the change in carbohydrates that occurred because of the citrus peel (CP) and the fermented Ecklonia cava disuse extract (ECD). For the test feed, the test feed was added so that the concentration of $\mathrm{CP}$ and ECD was $6 \%$ and mixed at a ratio of 1:1. The composition of the experimental feed is shown in Table 1.

\subsection{Survival Rate and Growth Rate Measurement Experiment According to Feed}

To measure the survival rates, abalones that naturally died at weeks $0,1,2,3,4,8$, and 12 were recorded in a timely manner. The dead abalones that were not attached to the shelter or tank wall were counted. Subjects that did not respond even when their feet and tentacles were stimulated with a glass rod were considered dead. In addition, to measure the growth of the abalones, we measured their change in size immediately after the start of the experiment, and on the 4 th, 8 th, and 12 th weeks. A digit caliper $(0.01 \mathrm{~mm})$ was used for the shell length and shell width (Figure 1), and a mobile scale $(0.01 \mathrm{~g})$ was used for the weight. Following the addition of ECD and CP to the abalone diet, the differences in growth were then compared and analyzed. 
Table 1. Ingredients (\%) of the experimental diets.

\begin{tabular}{ccccc}
\hline & Experimental Diets (\%) & & \\
\hline Ingredients & Control & CP & ECD & ECD + CP \\
CP (Citrus Peel) & & 6 & 6 & 3 \\
ECD (Ecklonia cava disuse) & & & 15.5 & 3 \\
Fish meal & 15.5 & 15.5 & 25 & 15.5 \\
Dextrin & 25 & 25 & 0.5 & 25 \\
Wheat flour & 6.5 & 0.5 & 20 & 0.5 \\
Casein & 20 & 20 & 23 & 23 \\
Sodium alginate & 23 & 23 & 4 & 4 \\
Mineral & 4 & 4 & 2 & 2 \\
Vitamin & 2 & 2 & 0.5 & 0.5 \\
Choline & 0.5 & 0.5 & 1.5 & 1.5 \\
Soybean oil & 1.5 & 1.5 & 2 & 2 \\
Fish oil & 2 & 2 & 100.0 & 100.0 \\
\hline Total & 100.0 & 100.0 & & 28.6 \\
Proximate analysis (\%) & & & 28.5 & 1.99 \\
Crude protein & 28.8 & 28.8 & 1.77 & 5.49 \\
Crude lipid & 1.47 & 2.22 & 5.27 & \\
\hline
\end{tabular}

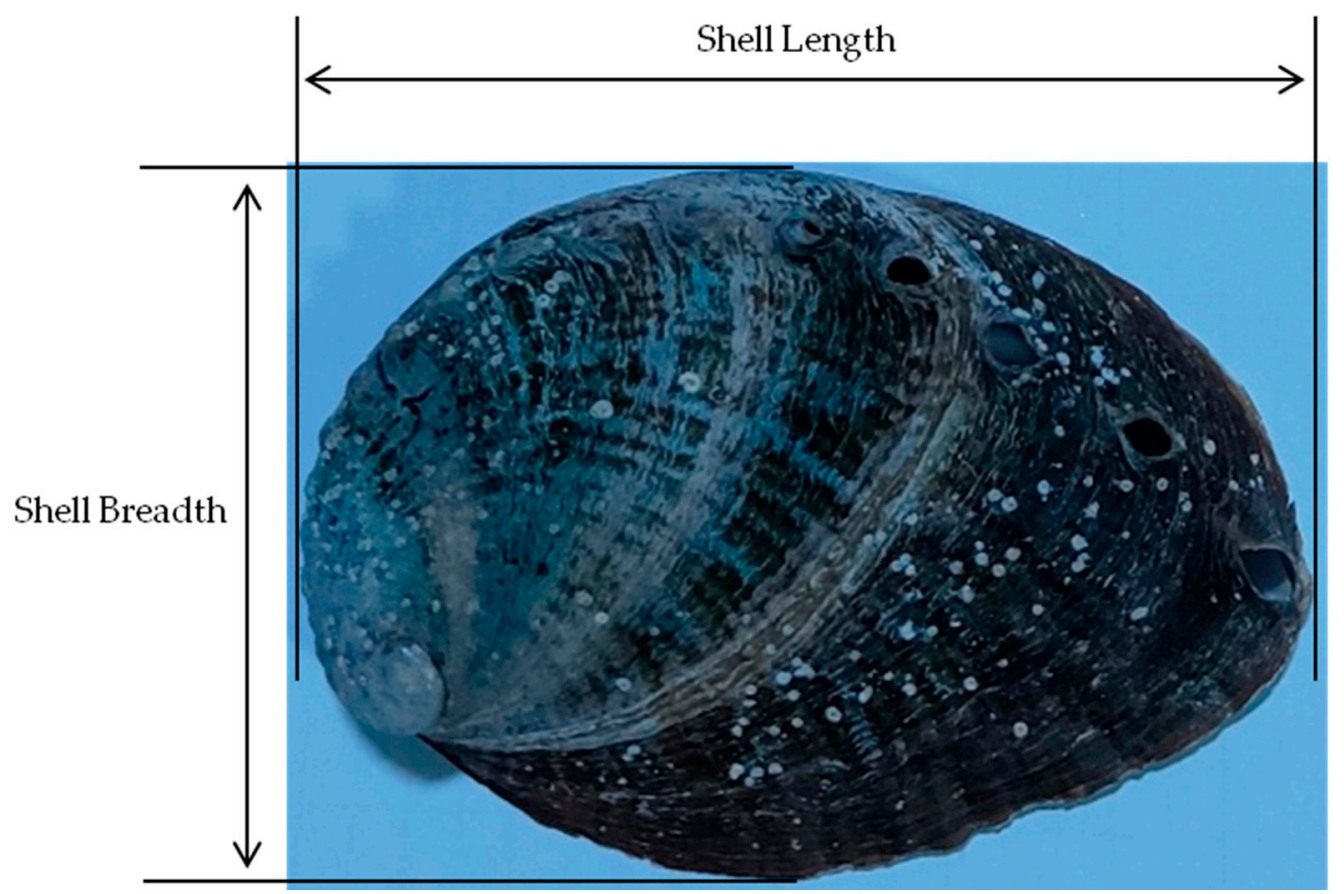

Figure 1. Abalone growth size measurement (sourced by the Author).

\subsection{Physiological Changes According to Rapid Low-Salinity Stress}

To determine the physiological changes in abalone due to rapid low-salinity stress, according to the difference in feed, 50 abalones were randomly selected from each experimental group, bred for 12 weeks, while the saline concentration was changed to $25 \mathrm{psu}$ from 33 psu of normal seawater. The physiological changes under low-salinity stress were confirmed by examining the survival rate, respiratory burst, and phenoloxidase activity at $0,3,6,12,24$, and $48 \mathrm{~h}$. 


\subsection{Statistics}

Statistical analysis was performed using one-way analysis of variance (ANOVA), followed by post-hoc $t$-tests, using the IBM SPSS 22 statistical program. Statistical significance was set at a significance level of 0.05 and the experiments were performed in triplicate. Additionally, we checked the normality test results.

\section{Results and Discussion}

\subsection{Changes in Survival Rate According to Feed}

The range of change in survival rate according to feed was not large. An individual abalone survived 2 weeks and naturally died on the 3rd week in the control experimental group. At 8 weeks, an individual died in the $\mathrm{CP}+\mathrm{ECD}$ experimental group, and at 12 weeks, an additional individual died in the control experimental group. In the experimental group where $\mathrm{CP}$ and ECD were added alone, no deaths occurred. Thus, compared to the control group, the test group fed both $\mathrm{CP}$ and ECD showed a higher survival rate (Table 2).

Table 2. Effect of dietary citrus pomace (CP) and Ecklonia cava disuse (ECD) on survival rate (\%) of abalone (H. discus).

\begin{tabular}{cccccccc}
\hline \multirow{2}{*}{ Diets } & \multicolumn{7}{c}{ Week } \\
\cline { 2 - 8 } & $\mathbf{0}$ & $\mathbf{1}$ & $\mathbf{2}$ & $\mathbf{3}$ & $\mathbf{4}$ & $\mathbf{8}$ & $\mathbf{1 2}$ \\
\hline Control & 100 & 100 & 100 & 94 & 94 & 94 & 92 \\
CP & 100 & 100 & 100 & 100 & 100 & 100 & 100 \\
ECD & 100 & 100 & 100 & 100 & 100 & 100 & 100 \\
CP + ECD & 100 & 100 & 100 & 100 & 100 & 98 & 98 \\
\hline
\end{tabular}

It is known that $\mathrm{CP}$ and ECD contain large amounts of phenols and other functional ingredients with antioxidant functions $[12,13,16]$. These functional substances are known to have very high antioxidant properties, including anti-inflammatory properties [18,19], and the high survival rate shown in this study is small.

\subsection{Changes in Growth Depending on Feed}

As illustrated in Figure 1, our research team measured the growth of shell breadth and shell length of abalones, caused by the feeding additives. Suspecting the addition of $\mathrm{CP}$ and ECD to the abalone diet would influence growth, an analysis of the size change at 12 weeks was performed. This analysis showed abalone lengths of $39.18 \pm 0.21 \mathrm{~mm}$ in the control group, $38.91 \pm 0.21 \mathrm{~mm}$ as the minimum value in the $\mathrm{CP}$ test group, and $39.99 \pm 0.19 \mathrm{~mm}$ as the maximum value in the ECD test group. Meanwhile, the $C P+E C D$ experimental group's lengths were recorded as $39.74 \pm 0.29 \mathrm{~mm}$ (Figure 2A). It was confirmed that the growth slowed after four weeks in the control and CP experimental groups, but the ECD and $\mathrm{CP}+\mathrm{ECD}$ experimental groups showed sustained growth that was significantly faster than that seen in the control (Figure 2A, $p<0.05$ ).

Nevertheless, the ECD alone test group showed the maximum value compared to the experimental group. When compared to other groups, the shell breadth at the 12th week showed a maximum value of $26.97 \pm 0.36 \mathrm{~mm}$ in the ECD test group. In the CP test group, the minimum value was $25.65 \pm 0.30 \mathrm{~mm}$. This result illustrated the rapid growth of the shell breadth, but there was no significant difference (Figure 2B, $p>0.05$ ). As a result of this experiment with our abalone samples, we could conclude the shell breadth of the abalones grows to $75 \%$ compared to the shell length. 

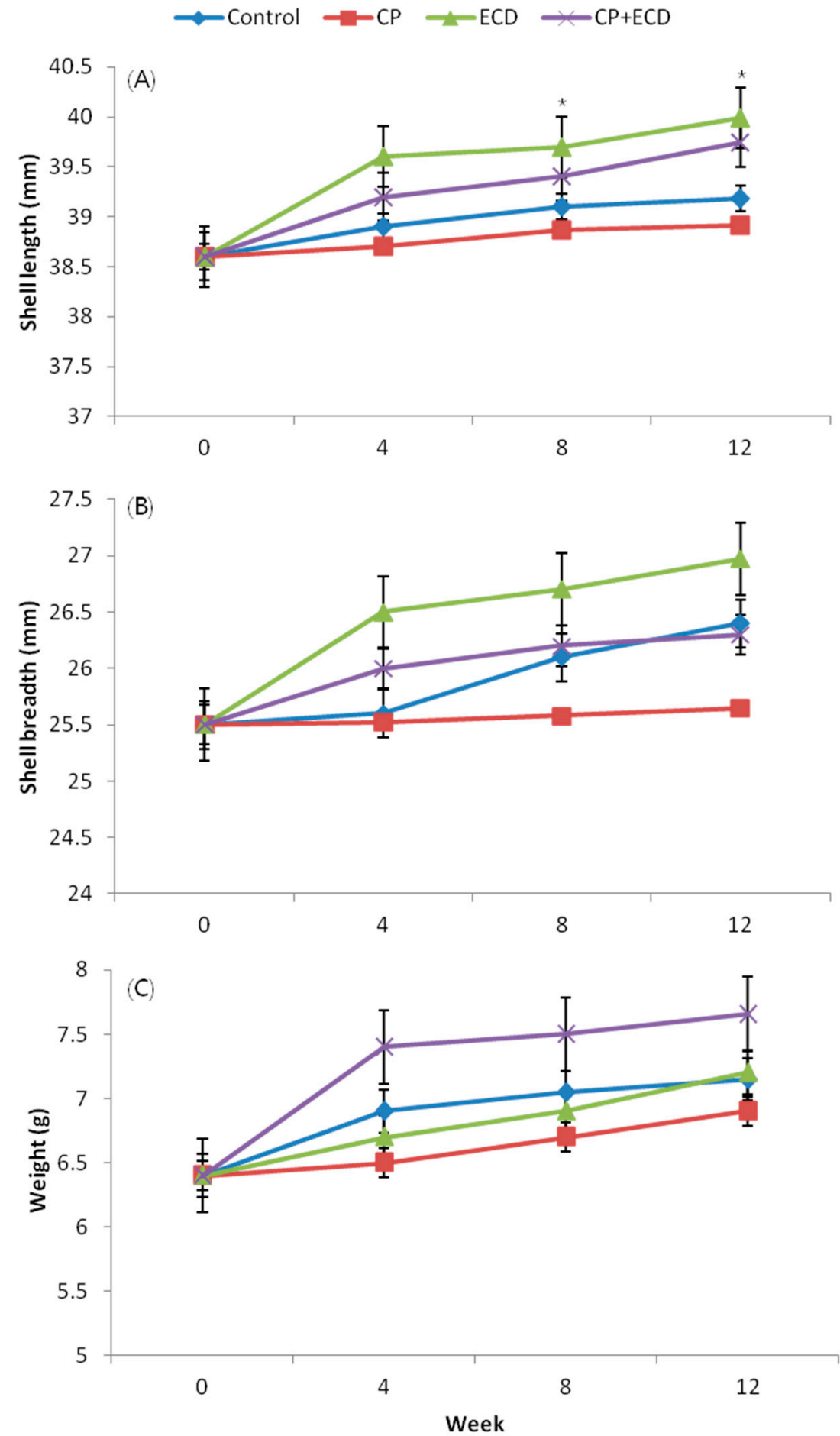

Figure 2. Variations in the growth of abalone (H. discus) after feeding the experimental diets supplemented with $\mathrm{CP}(6 \%)$, ECD $(6 \%)$, and CP $+\mathrm{ECD}(3 \%+3 \%)$ for three months (twelve weeks). (A) Shell length, (B) shell breadth, (C) total weight. Vertical bars in the figure show the SE of the means from three experimentations. ${ }^{*} p<0.05$ for each control.

In the case of the total weight of the abalone, it was $7.66 \pm 0.30 \mathrm{~g}$ in the $\mathrm{CP}+\mathrm{ECD}$ experimental group and $7.20 \pm 0.35 \mathrm{~g}$ in the ECD experimental group at 12 weeks, which was the end of the experiment. This shows a value higher than the $7.15 \mathrm{~g}$ seen in the control group, but there was no significant difference between these values.

Adding more ECD, we observed a higher growth rate of the abalone. However, when more $\mathrm{CP}$ was added, there was no significant difference when compared to the control 
group. Rather, the values indicate that the higher the $\mathrm{CP}$ content, the more likely it is that it will not positively affect growth. In the case of ECD, fiber, inorganic substances, and functional phenols are abundant in seaweed. Even if the algae content was high, the algae-eating abalone did not have a significant response in growth. Nevertheless, because $\mathrm{CP}$ increased the survival rate, we may consider having potential as a useful ingredient for abalone general feed.

In addition, if research on $\mathrm{CP}^{\prime}$ 's beneficial properties proceeds, we could estimate that $\mathrm{CP}$, considered merely waste in the Jeju area, will play a big role in creating newfound value, as well as preserving the environment. Therefore, in this study, the functions of CP and ECD were studied after stress was imposed on the abalone to study their potential benefits.

\subsection{Changes in Survival Rates Induced by Low-Salinity Stress}

As a result of the previous study, it was found that a single supply of ECD has an effect on the survival rate and growth (Figure 2 and Table 3). In order to determine whether the effects of CP and ECD are related to the increase in immunity, changes in the survival rate, antioxidant enzyme activity (SOD: superoxide dismutase and CAT: catalase), lysozyme activity, respiratory burst activity, and phenoloxidase activity were analyzed after artificially lowering the salinity concentration. Following the experimental testing-feed injection, there were abalones in all experimental groups that died $48 \mathrm{~h}$ after the salinity rapidly changed.

Table 3. Survival rate (\%) of the abalone (H. discus) exposed to acute water-salinity stress for $48 \mathrm{~h}$ after feeding on the experimental diets supplemented with CP $(6 \%), \mathrm{ECD}(6 \%)$, and CP + ECD $(3 \%+3 \%)$ for 12 weeks.

\begin{tabular}{ccccccc}
\hline \multirow{2}{*}{ Diets } & \multicolumn{7}{c}{ Time (h) } \\
\cline { 2 - 6 } & $\mathbf{0}$ & $\mathbf{3}$ & $\mathbf{6}$ & $\mathbf{1 2}$ & $\mathbf{2 4}$ & $\mathbf{4 8}$ \\
\hline Control & 100 & 100 & 100 & 100 & 100 & 74.1 \\
CP & 100 & 100 & 100 & 100 & 100 & 88.9 \\
ECD & 100 & 100 & 100 & 100 & 100 & 96.3 \\
CP + ECD & 100 & 100 & 100 & 100 & 100 & 70.4 \\
\hline
\end{tabular}

In particular, the $\mathrm{CP}+\mathrm{ECD}$ test group and the control group showed low survival rates of $70.4 \%$ and $74.1 \%$, respectively (Table 3 ). However, in the experimental group that was administered CP and ECD alone, survival rates of $88.9 \%$ and $96.3 \%$, respectively, were shown, which held a higher survival rate than the control group (Table 3).

In the case of SOD, the change in antioxidant enzyme activity did not show a significant difference in all experimental groups $48 \mathrm{~h}$ after the application of low-salinity stress (Figure 3A). However, regarding CAT, the ECD-only-supplied group, CP-only-supplied group, and the CP + ECD-supplied group showed high values (Figure 3B).

In the case of SOD and CAT, when raising abalone in low salinity, the levels are reported to increase [19]; the results of this experiment also showed an increase in the level of CAT. However, in the case of ECD, it is assumed that the low level is maintained by suppressing the production of free oxygen radicals that are normally triggered by external stress. The survival rate is assumed to have increased accordingly.

Lysozyme activity was also lowered by the low-salinity stimulation, but the pre-stress level was maintained only in the experimental group fed with ECD alone (Figure 4). These results also indicate that it is highly likely that the survival of abalone was affected by a factor similarly affecting the activity of CAT, which is changed by the response action. However, respiratory burst activity increases when phagocytic cells are either engaged in phagocytosis or when they are stimulated by other means. These conditions increase oxygen consumption and cause the release of large amounts of oxygen radicals (ROIs: $\mathrm{O}_{2}{ }^{-}, \mathrm{OH}^{-}, \mathrm{H}_{2} \mathrm{O}_{2}$ ) [20]. We have found that this process can play a quite important role in killing pathogens. 
nControl $\approx \mathrm{CP} \backsim \mathrm{ECD} \backsim \mathrm{CP}+\mathrm{ECD}$

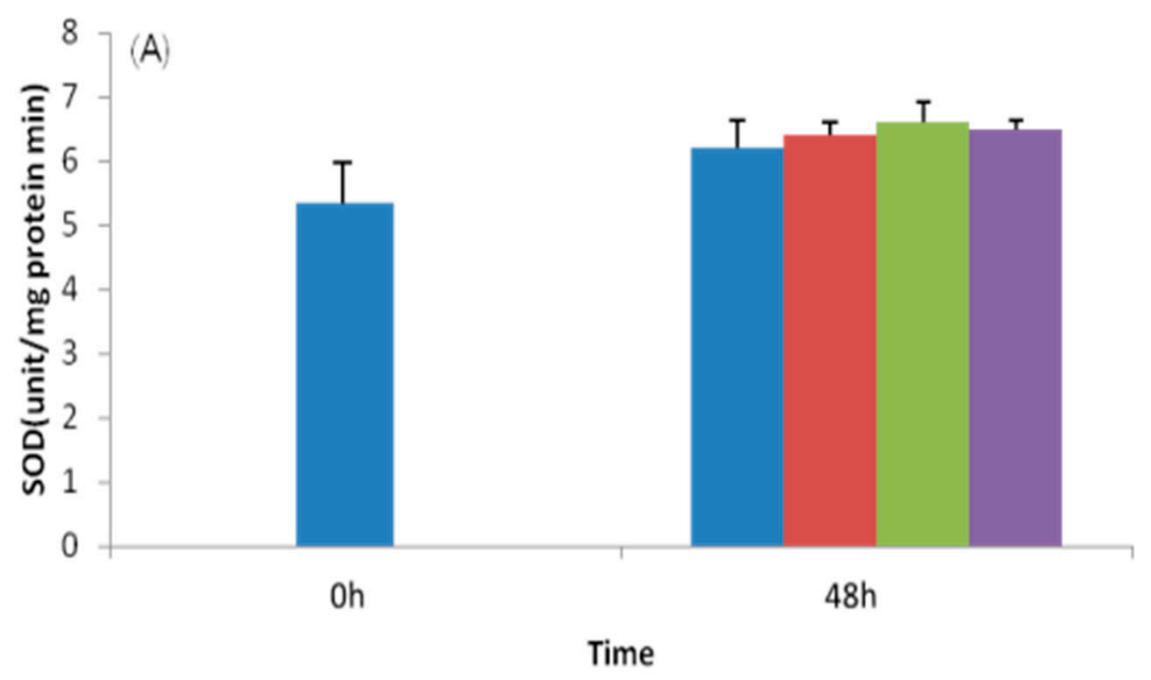

nControl $\square C P=E C D=C P+E C D$

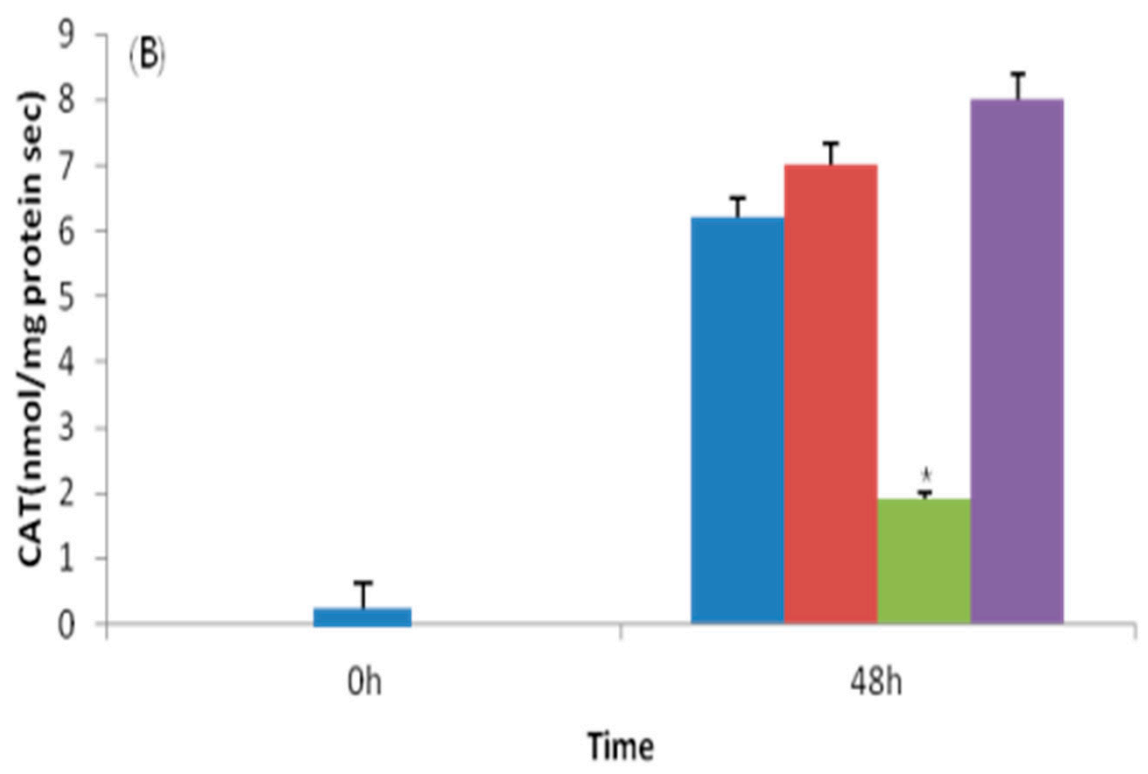

Figure 3. Effect of acute water-salinity stress for $48 \mathrm{~h}$ on the change of superoxide dismutase (SOD) (A) and catalase (CAT) levels (B) in the abalone ( $H$. discus). This was assessed after they were fed on the experimental diets supplemented with CP $(6 \%)$, ECD $(6 \%)$, and CP + ECD $(3 \%+3 \%)$ for 12 weeks. Vertical bars represent the SE of the means of three experiments. ${ }^{*} p<0.05$ for the control level at $48 \mathrm{~h}$.

As a result of this experiment, we confirmed that the respiratory burst activity in the control group significantly increased at $48 \mathrm{~h}$ compared to at $0 \mathrm{~h}$ and no significant change was observed in the other experimental groups (Figure 5). In low salinity, it was reported that the abalone respiratory burst activity remains almost unchanged [21], but the results of this study showed significantly higher values in the control group (Figure 5). 


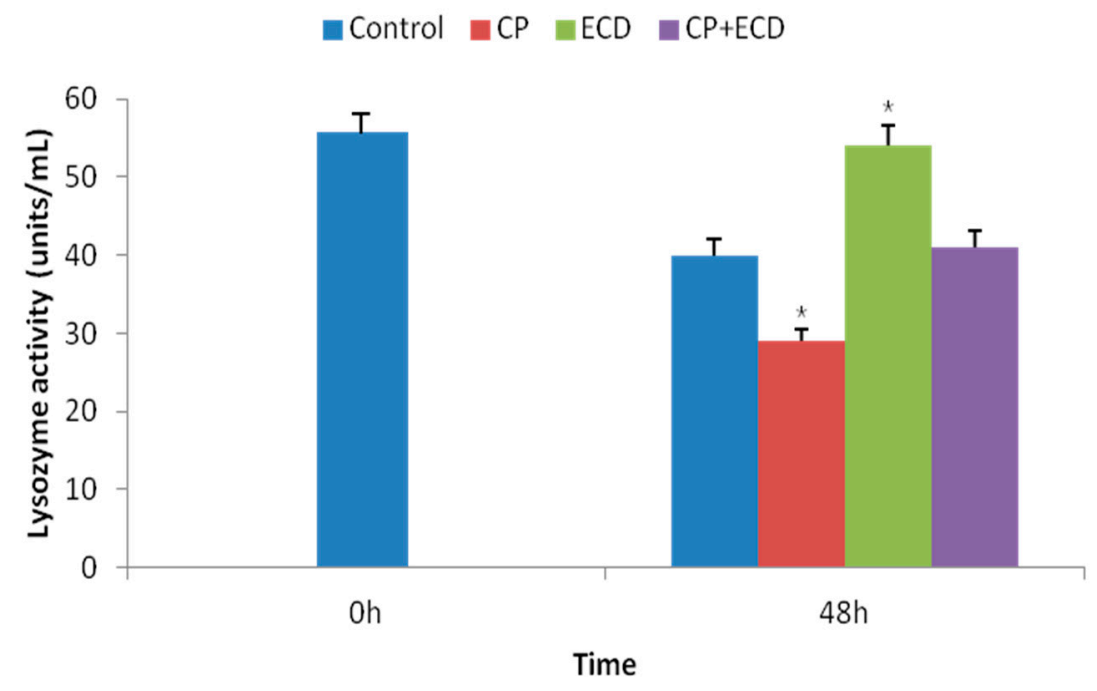

Figure 4. Effect of acute water-salinity stress for $48 \mathrm{~h}$ on the activity of lysozyme in the abalone (H. discus) after feeding on the experimental diets supplemented with CP (6\%), ECD (6\%), and $\mathrm{CP}+\mathrm{ECD}(3 \%+3 \%)$ for 12 weeks. Vertical bars represent the SE of the means of three experiments. $* p<0.05$ for control level at $48 \mathrm{~h}$.

- Control $\square \mathrm{CP} \quad \mathrm{ECD} \quad \mathrm{CP}+\mathrm{ECD}$

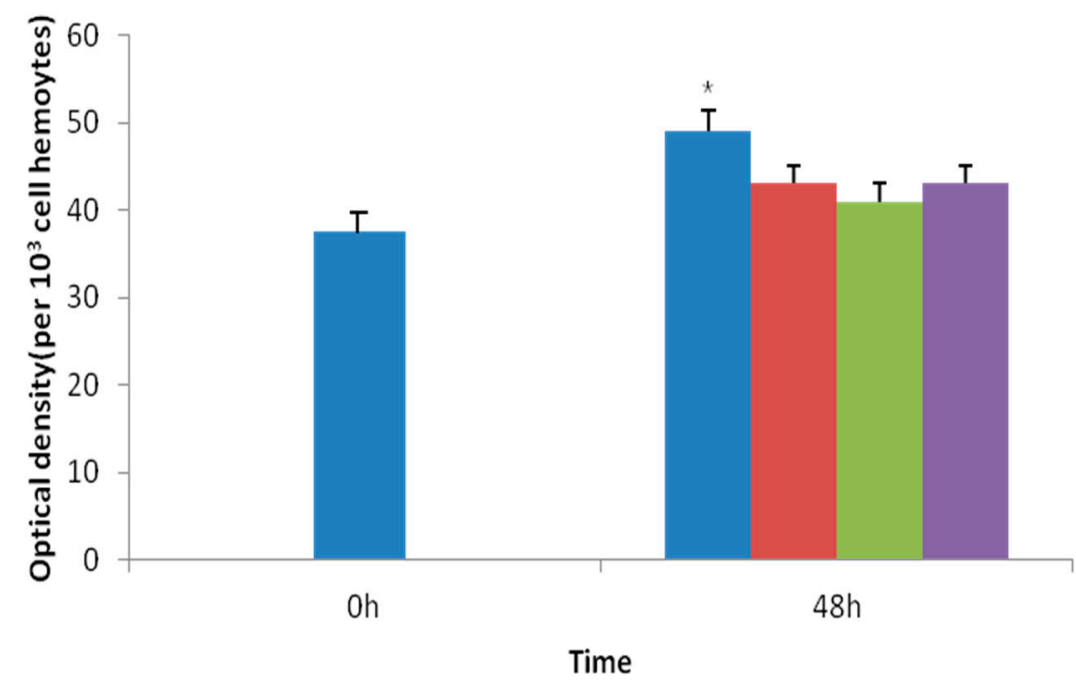

Figure 5. Effect of acute water-salinity stress for $48 \mathrm{~h}$ on respiratory burst activity in the abalone (H. discus) after feeding on the experimental diets supplemented with CP (6\%), ECD (6\%), and $\mathrm{CP}+\mathrm{ECD}(3 \%+3 \%)$ for 12 weeks. Vertical bars represent the SE of the means of three experiments. * $p<0.05$ for control level at $48 \mathrm{~h}$.

Because CP's and ECD's anti-inflammatory and antioxidant functions are already well known $[12,13,22]$, it can be cautiously assumed that they may be responsible for maintaining a certain level of resistance to pathogens during the pre-immunological phase of the abalone, as this study's results suggest.

Our research team assumes that the polyphenol substances in CP and ECD contain phlorotannin and flavonoid compounds. If this is the case, it can be inferred that the abalones built a tolerance to certain pathogens. This tolerance allows the abalones to maintain homeostasis when exposed to the pathogens. Therefore, based on the results of this study, further pathogenicity experimental research will be required to draw empirical conclusions that can contribute to the abalone industry. 
The immune system of invertebrates is mainly an innate immune system. Phenoloxidase is known to be activated, in the form of pro-phenoloxidase, by bacteria and other microorganisms in the body [23]. Phenoloxidase activity significantly decreased at $48 \mathrm{~h}$ compared to $0 \mathrm{~h}$ in the $\mathrm{CP}$ experimental group. Furthermore, it was confirmed that the ECD-only group had a higher value than that of the control (Figure 6).

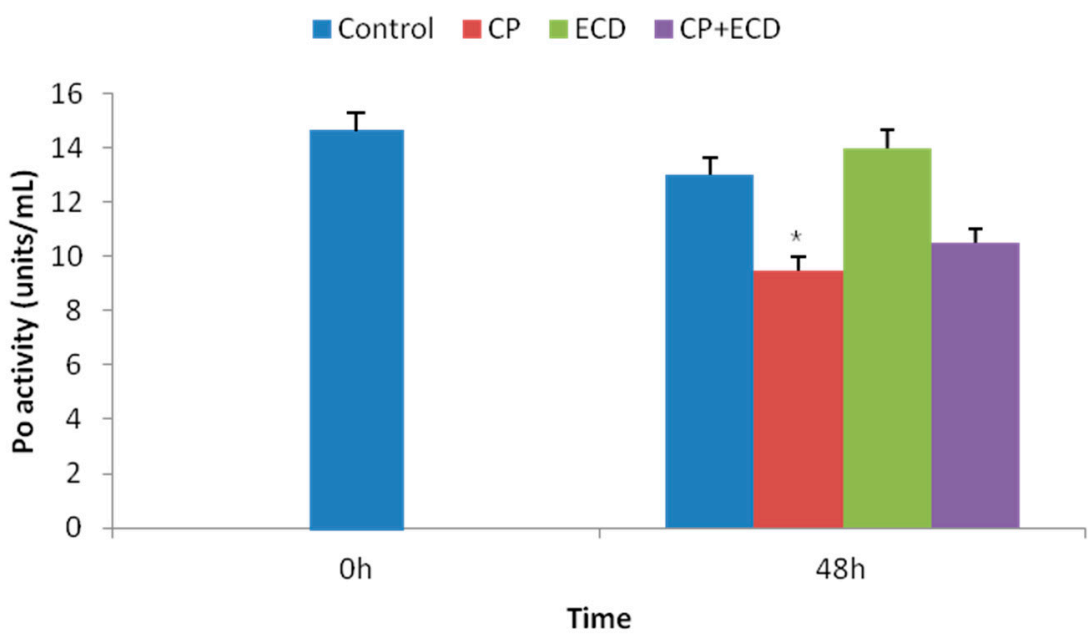

Figure 6. Effect of acute water-salinity stress for $48 \mathrm{~h}$ on phenoloxidase activity in abalone (H. discus) after feeding on the experimental diets supplemented with CP (6\%), ECD (6\%), and CP + ECD $(3 \%+3 \%)$ for 12 weeks. Vertical bars represent the SE of the means of three experiments. ${ }^{*} p<0.05$ for control level at $48 \mathrm{~h}$.

Summarizing the above-mentioned results, our research team found that $\mathrm{CP}$ and ECD feeding showed significant effects on the survival rate. However, ECD showed the most significant effect in the growth and physiology of the abalones. In particular, the experimental group only supplied with ECD showed significantly better results than the other experimental groups in CAT, lysozyme, and phenoloxidase activity; thus it is considered that feeding abalone using Ecklonia can be highly useful. The biological effects of citrus fruit are somewhat inferior to Ecklonia, but it showed a meaningful result in the aspect of the survival rate in our study.

In summary, supplying both $\mathrm{CP}$ and ECD in the abalone diet showed positive results, but ECD alone showed remarkably good effects on growth in the experimental group. In particular, CAT, lysozyme, and phenoloxidase activity had the best results in the experimental group where only ECD was added. We determine that incorporating feed with the potential to maximize growth and resistance can be extremely useful for abalone aquaculture farming. However, in order to further support these results, further research is needed when abalones are exposed to higher water temperatures in their natural habitats, which reach up to 30 degrees Celsius in the summer.

\section{Conclusions}

Our research team analyzed how incorporating $\mathrm{CP}$ and ECD into the abalone diet, while they were exposed to a low-salinity environment, affected the abalone growth and immune response. Results indicated that the experimental group whose feed was supplemented with only ECD had the most significant effects on growth and immunity. Based on the results of this study, further studies on high water temperature stress are needed in the future.

Author Contributions: M.-S.J. and C.-Y.H. provided direction to the research work and participated in the research. M.-S.J. and C.-Y.H. performed the literature review and collected relevant data and M.-S.J. wrote the manuscript. Additionally, M.-S.J. searched and collected data on irradiation 
experiments; he searched and collected literature and evidence. C.-Y.H. revised the paper. All authors have read and agreed to the published version of the manuscript.

Funding: This research received no external funding.

Data Availability Statement: Not applicable.

Acknowledgments: We appreciate the productive suggestion from editors and anonymous reviewers and would like to give our thanks to them.

Conflicts of Interest: The authors declare no conflict of interest.

\section{References}

1. Kim, B.H.; Park, M.W.; Kim, T.I.; Son, M.H.; Lee, S.I. The effect of growth and survival rate on feeding rate of abalone, Haliotis discus hannai, rearing in net cage culture or indoor tank culture. Korean J. Malacol. 2014, 30, 227-234. [CrossRef]

2. Lee, S.M.; Yun, S.J.; Hur, S.B. Evaluation of dietary protein sources for abalone (Haliotis discus hannai). J. Aquacult. 1998, 11, 19-29.

3. Kim, B.H.; Lee, S.M.; Go, C.S.; Kim, J.W.; Mueong, J.I. Optimum stocking density of juvenile abalone (Haliotis discus hannai) fed the formulated diet or macroalgae (Undaria). Korean J. Fish. Aquat. Sci. 1998, 31, 869-874.

4. Lee, S.M.; Yun, S.Y.; Min, K.S.; Yoo, S.K. Evaluation of dietary carbohydrate sources for juvenile abalone (Haliotis discus hannai). J. Aquacult. 1998, 11, 133-140.

5. Lee, S.M.; Lim, Y.S.; Moon, Y.B.; Yoo, S.K.; Rho, S. Effect of supplemental macroalgae and spirulina in the diets on growth performance in juvenile abalone (Haliotis discus hannai). J. Aquacult. 1998, 11, 31-38.

6. Viana, M.T.; Lopez, L.M.; Salas, A. Diet development for juvenile abalone (Haliotis fulgens). Evaluation of two artificial diets and macroalgae. Aquaculture 1993, 117, 149-156. [CrossRef]

7. Mai, K.; Mercer, J.P.; Donlon, J. Comparative studies on the nutrition of two species of abalone (Haliotis tuberculata) L. and (Haliotis discus hannai) Ino. III. Responses of abalone to various levels of dietary lipid. Aquaculture 1995, 134, 65-80. [CrossRef]

8. Uki, N.; Kemuyama, A.; Watanabe, T. Development of semipurified test diets for abalone. Bull. Jpn. Soc. Sci. Fish. 1985, 51, 1825-1833. [CrossRef]

9. Uki, N.; Kemuyama, A.; Watanabe, T. Nutrient evaluation of several sources in diets for abalone (Haliotis discus hannai). Bull. Jpn. Soc. Sci. Fish. 1985, 51, 1835-1839. [CrossRef]

10. Uki, N.; Kemuyama, A.; Watanabe, T. Optimum protein level in diets for abalone. Bull. Jpn. Soc. Sci. Fish. 1986, 52, 1005-1012. [CrossRef]

11. Uki, N.; Sugiura, M.; Watanabe, T. Requirement of essential fatty acids in the abalone (Haliotis discus hannai). Bull. Jpn. Soc. Sci. Fish. 1986, 52, 1013-1023. [CrossRef]

12. Mouly, P.P.M.; Arzouyan, C.G.; Gaydou, E.M.; Rstienne, J.M. Differentiation of citrus juices by factorial discriminant analysis using liquid chromatography of flavanone glycosides. J. Agric. Food Chem. 1994, 42, 70-79. [CrossRef]

13. Rouseff, R.L.; Martin, S.F.; Youtsey, C.O. Quantitative survey of narirutin, naringin, hesperidin and neohesperidin in citrus. J. Agric. Food Chem. 1987, 35, 1027-1030. [CrossRef]

14. Yun, A.Y.; Lee, K.W.; Kim, P.Y.; Jeong, H.S.; Kim, H.S.; Cho, S.H.; Kim, T.H. Substitution effect of Undaria pinnatifida with citrus(Citrus unshiu, Marcovitch) peel by-product in feed on growth, body composition and air exposure stressor of juvenile abalone (Haliotis discus, Reeve 1846). Aquac. Nutr. 2020, 26, 466-476. [CrossRef]

15. Yasantha, A.; Jeon, Y.J. Screening for angiotensin 1-converting enzyme inhibitory activity of Ecklonia cava. J. Food Sci. Nutr. 2005, 10, 134-139. [CrossRef]

16. Kim, K.N.; Lee, K.W.; Song, C.B.; Jeon, Y.J. Cytotoxin activities of green and brown seaweeds collected from jeju island against four tumor cell lines. J. Food Sci. Nutr. 2006, 11, 17-24. [CrossRef]

17. Lee, S.H.; Kim, K.N.; Cha, S.H.; Ahn, G.N.; Jeon, Y.J. Comparison of antioxidant activities of enzymatic and methanolic extracts from Ecklonia cava stem and leave. J. Korean Soc. Food Sci. Nutr. 2006, 35, 1139-1145. [CrossRef]

18. Manthey, J.A.; Grohmann, K. Phenols in citrus peel by products. Concentrations of hydroxycinnamates and polymethoxylated flavones in citrus peel molasses. J. Agric. Food Chem. 2001, 49, 3268-3273. [CrossRef]

19. Latorre, D.; Pudu, P.; Valenti, P.; Gessani, S. Reciprocal interactions between lactoferrin and bactericidal endotoxins and their role in the regulation of the immune response. Toxins 2010, 2, 54-68. [CrossRef]

20. Siwicki, A.K.; Anderson, D.P.; Rumsey, G.L. Dietary intake of immunostimulants by rainbow trout affects non-specific immunity and protection against furunculosis. Vet. Immunol. Immunopathol. 1994, 41, 125-139. [CrossRef]

21. Jwa, M.S.; Kang, K.P.; Choe, M.K.; Yeo, I.K. Effects of low salinity stresses on the physiological of disc abalone (Haliotis discus discus). J. Fish Pathol. 2009, 22, 293-303.

22. Senevirathne, M.; Jeon, Y.J.; Ha, J.H.; Kim, S.H. Effective drying of citrus by-product by high speed drying: A novel drying technique and their antioxidant activity. J. Food Eng. 2009, 92, 157-163. [CrossRef]

23. Johnson, J.K.; Rocheleau, T.A.; Hillyer, J.F.; Chen, C.C.; Li, J.; Christensen, B.M. A potential role for phenylalanine hydroxylase in mosquito immune responses. Insect Biochem. Mol. Biol. 2003, 33, 345-354. [CrossRef] 